\title{
MÍDIA-EDUCAÇÃO: CONCEITOS, HISTÓRIA E PERSPECTIVAS
}

\author{
EVELYNE BÉVORT* \\ Maria Luiza BeLloni*
}

\begin{abstract}
RESUMO: Para que a sociedade da informação seja uma sociedade plural, inclusiva e participativa, hoje, mais do que nunca, é necessário oferecer a todos os cidadãos, principalmente aos jovens, as competências para saber compreender a informação, ter o distanciamento necessário à análise crítica, utilizar e produzir informações e todo tipo de mensagens. Esta convicção inspirou este artigo, cujo objetivo é apresentar algumas tendências atuais da mídia-educação no mundo, seus conceitos e açôes, buscando contribuir para seu desenvolvimento no Brasil. Mídia-educação é importante porque vivemos num mundo onde as mídias estão onipresentes, sendo preciso considerar sua importância na vida social, particularmente no que diz respeito aos jovens. Promover a mídia-educação é importante também porque as defasagens, que separam muitas vezes os sistemas educacionais do mundo que nos rodeia, prejudicam a formação das novas geraçóes para a vida adulta.
\end{abstract}

Palavras-chave: Mídia-educação. Educação para as mídias. Educomunicação. Comunicação e educação.

MEDiA EDUCATION: CONCEPTS, HISTORY AND PERSPECTIVES

ABSTRACT: In order to build a diverse and inclusive society of information, it is more than ever necessary to give all citizens and particularly young people the skills enabling them to understand

Educ. Soc., Campinas, vol. 30, n. 109, p. 1081-1102, set./dez. 2009

Disponível em <http://www.cedes.unicamp.br> 
information, take the distance necessary for critical analysis, use and produce informations and all kinds of messages. This conviction inspired this article which objective is to present the last trends of media education in the word, its concepts and actions, in order to contribute for its development in Brazil. Media education is important because we live in a world where the medias are omnipresent and we have to take in consideration their increasing importance in social life, particularly as concerns the younger generations. To promote media education is important also because the gap, which often separates education systems and th world which surrounds us, impairs preparations for the adult life of younger generations.

Key words: Media education. Media literacy. Educommunication.

Communication and education.

Introdução: relevância e obstáculos

E

ste texto pretende contribuir para a reflexão sobre a mídia-educação e sobre a formação de profissionais da educação. Embora todas as afirmações nele contidas tenham base científica e sejam resultado de reflexão teórica, trata-se de um texto militante, que defende uma ideia e uma prática indispensáveis para que a formação de educadores cumpra sua função social: a ideia de que não pode haver cidadania sem apropriação crítica e criativa, por todos os cidadãos, das mídias que o progresso técnico coloca à disposição da sociedade; e a prática de integrar estas mídias nos processos educacionais em todos os níveis e modalidades, sem o que a educação que oferecemos às novas geraçôes continuará sendo incompleta e anacrônica, em total dissonância com as demandas sociais e culturais. Com esta pretensão, nos inscrevemos perfeitamente na tradição da mídia-educação, que sempre foi uma atividade militante, como bem lembrou G. Jacquinot (UNESCO, 2007).

Mídia-educação é um campo relativamente novo, com dificuldades para se consolidar, entre as quais a mais importante é, sem dúvida, sua pouca importância na formação inicial e continuada de profissionais da educação. A esta dificuldade maior, cuja mudança é condição sine qua non para o desenvolvimento da mídia-educação, acrescentamse outros obstáculos importantes: i) ausência de preocupação com a 
formação das novas gerações para a apropriação crítica e criativa das novas tecnologias de informaçãao e comunicação (TIC); ${ }^{1}$ ii) indefinição de políticas públicas e insuficiência de recursos para ações e pesquisas; iii) confusões conceituais, práticas inadequadas, "receitas prontas" para a sala de aula, em lugar da reflexão sobre o tema na formação de educadores; iv) influência de abordagens baseadas nos efeitos negativos das mídias que tendem a baní-las da educação, em lugar da compreensão das implicações sociais, culturais e educacionais; v) integração das TIC à escola de modo meramente instrumental, sem a reflexão sobre mensagens e contextos de produção.

Evidentemente, estas dificuldades ocorrem de modo extremamente diferenciado nos diferentes países e regiōes do planeta, mas se pode observar tendências comuns. Tais dificuldades e obstáculos explicam-se em grande parte, no plano epistemológico, pelas características estruturais do campo da mídia-educação, que se situa na intersecção dos campos da educação e da comunicação, tendo, pois, enquanto campo de estudo e de intervenção, as mesmas características destes dois campos, complexos em razão de suas ambivalências estruturais: são ao mesmo tempo teóricos e práticos, exigindo para sua compreensão abordagens interdisciplinares que colocam em relação diferentes disciplinas das ciências humanas. Não por acaso, as ciências (ou teorias) da educação e as ciências (ou teorias) da comunicação se declinam no plural.

A mídia-educação é parte essencial dos processos de socialização das novas geraçôes, mas não apenas, pois deve incluir também populações adultas, numa concepção de educação ao longo da vida. Trata-se de um elemento essencial dos processos de produção, reprodução e transmissão da cultura, pois as mídias fazem parte da cultura contemporânea e nela desempenham papéis cada vez mais importantes, sua apropriação crítica e criativa, sendo, pois, imprescindível para o exercício da cidadania. Também é preciso ressaltar que as mídias são importantes e sofisticados dispositivos técnicos de comunicação que atuam em muitas esferas da vida social, não apenas com funções efetivas de controle social (político, ideológico...), mas também gerando novos modos de perceber a realidade, de aprender, de produzir e difundir conhecimentos e informações. São, portanto, extremamente importantes na vida das novas gerações, funcionando como instituiçôes de socialização, uma espécie de "escola paralela", 
mais interessante e atrativa que a instituição escolar, na qual crianças e adolescentes não apenas aprendem coisas novas, mas também, e talvez principalmente, desenvolvem novas habilidades cognitivas, ou seja, "novos modos de aprender", mais autônomos e colaborativos, ainda ignorados por professores e especialistas (Porcher, 1974; Perriault, 2002; Belloni \& Gomes, 2008; Belloni et al., 2007; Belloni, s/d).

Do ponto de vista conceitual, a questão mais importante é a integração destes dispositivos técnicos aos processos educacionais e comunicacionais. Nas sociedades contemporâneas, esta integração tende a ocorrer de modo bastante desigual: ela é alta e rápida nos processos de comunicação, onde os agentes (as "mídias") se apropriam imediatamente das novas tecnologias e as utilizam numa lógica de mercado; e tende a ser muito baixa nos processos educacionais, cujas características estruturais e institucionais dificultam mudanças e inovações pedagógicas e organizacionais, que a integração de novos dispositivos técnicos acarreta. Além desta desigualdade estrutural, é preciso ressaltar outras, igualmente importantes: o acesso e a apropriação das TIC ocorrem também de modo muito desigual, segundo as classes sociais e as regióes do planeta.

A integração das TIC na escola, em todos os seus níveis, é fundamental porque estas técnicas já estão presentes na vida de todas as crianças e adolescentes e funcionam - de modo desigual, real ou virtual - como agências de socialização, concorrendo com a escola e a família. Uma de suas funções é contribuir para compensar as desigualdades que tendem a afastar a escola dos jovens e, por consequência, a dificultar que a instituição escolar cumpra efetivamente sua missão de formar o cidadão e o indivíduo competente. Por isso, é importante considerar esta integração, na perspectiva da mídia-educação, em suas duas dimensões inseparáveis: objeto de estudo e ferramenta pedagógica, ou seja, como educação para as mídias, com as mídias, sobre as mídias e pelas mídias. Somente assim a escola poderá cumprir sua missão de formar as novas gerações para a apropriação crítica e criativa das mídias, o que significa ensinar a aprender a ser um cidadão capaz de usar as TIC como meios de participação e expressão de suas próprias opiniōes, saberes e criatividade (Belloni, 2002, 2001a e 2001b; Gonnet, 2004; Jacquinot, 2002; Bévort, 2002). 
Histórico: conceito em evolução, práticas em dispersão

Em sua fase pioneira, nos anos de 1950/1960, na Europa, nos Estados Unidos e no Canadá, o interesse pela mídia-educação aparece como uma preocupação com os aspectos políticos e ideológicos decorrentes da crescente importância das mídias na vida cotidiana e se refere mais à informação sobre a atualidade, principalmente política. À medida que esta importância vai crescendo, os outros aspectos dos conteúdos midiáticos (ficção, entretenimento) vão revelando sua eficácia comunicacional e passam a integrar aquela preocupação. No entanto, ainda hoje nota-se uma ênfase na informação, em muitas propostas e ações de mídia-educação. Os perigos de influência ideológica, o receio de uniformização estética e de empobrecimento cultural pela padronização de fórmulas de sucesso do cinema e do rádio, agora estandardizadas pela televisão, levaram jornalistas e educadores a se preocuparem com a formação de crianças e jovens para uma "leitura crítica" dos meios de comunicação de massa. As abordagens mais influentes focalizavam os efeitos da "exposição" às mídias de massa da época: efeitos ideológicos, político-eleitorais, éticos e sobre comportamentos infantis e adolescentes (violência, sexualidade...). Pesquisadores de diferentes horizontes, educadores, jornalistas e grupos religiosos buscavam minimizar a importância dos efeitos das mídias ou, ao contrário, demonstrar seus perigos. Ao mesmo tempo, à medida que os processos de comunicação evoluíam, divididos entre dois modelos concorrentes - de um lado, a indústria cultural, com tendências à mundialização, e de outro, o monopólio estatal limitado aos territórios nacionais -, a publicidade comercial e o avanço tecnológico iam construindo o modelo do futuro, o de hoje: a produção industrializada e mundializada da cultura e da comunicação, inclusive do setor que parecia mais impróprio à globalização: o da informação.

A expressão "educação para as mídias" ou "mídia-educação" aparece em organismos internacionais, particularmente na UNESCO, nos anos de 1960 e, num primeiro momento, refere-se de modo um tanto confuso à capacidade destes novos meios de comunicação de alfabetizarem em grande escala populações privadas de estruturas de ensino e de equipes de pessoal qualificado, ou seja, às virtudes educacionais das mídias de massa como meios de educação a distância. A mesma expressão é usada para exprimir a preocupação de educadores, intelectuais e 
decisores com a influência cultural destas mídias, os riscos de manipulação política, comercial e publicitária e a consequente necessidade de desenvolver abordagens críticas (Gonnet, 2004, p. 23). Em 1973, uma tentativa de definição aponta para o surgimento de um novo campo de ação:

Por mídia-educação convém entender o estudo, o ensino e a aprendizagem dos meios modernos de comunicação e expressão, considerados como parte de um campo específico e autônomo de conhecimentos, na teoria e na prática pedagógicas, o que é diferente de sua utilização como auxiliar para o ensino e a aprendizagem em outros campos do conhecimento, tais como a matemática, a ciểncia e a geografia. (UNESCO, 1984)

Nesta primeira definição vemos claramente a distinção das duas dimensões da mídia-educação e a ênfase exclusiva em sua dimensão de objeto de estudo, isto é, de leitura crítica das mensagens midiáticas, deixando a dimensão ferramenta pedagógica para outra área que irá conhecer, nos anos de 1970, significativo desenvolvimento, especialmente nos Estados Unidos e na América Latina: a tecnologia educacional, como ferramenta do planejamento de educação, vista como panacéia para melhorar qualitativa e quantitativamente os sistemas educacionais nos países do terceiro mundo (Belloni \& Subtil, 2002). Entende-se, a partir de então, por "mídia-educação", a formação para a leitura crítica das mídias em geral, independentemente do suporte técnico (impresso, rádio, cinema, televisão). As finalidades concernem à formação das novas gerações para uma compreensão distanciada, analítica e crítica das mensagens midiáticas, tanto de seus conteúdos quanto dos contextos políticos e econômicos de sua produção. Nos Estados Unidos, uma abordagem tecnicista e pragmática se acrescenta a esta leitura crítica de conteúdos, enfatizando a apropriação dos aspectos técnicos de produção das messagens midiáticas. Em 1979, surge uma nova definição que tenta abranger o conjunto do fenômeno e melhor definir o objeto da mídia-educação, que comprenderá, então:

Todas as maneiras de estudar, aprender e ensinar em todos os níveis (...) e em todas as circunstâncias, a história, a criação, a utilização e a avaliação das mídias enquanto artes práticas e técnicas, bem como o lugar que elas ocupam na sociedade, seu impacto social, as implicações da comunicação mediatizada, a participação, a modificação do modo de percepção que elas engendram, o papel do trabalho criativo e o acesso às mídias. (UNESCO, 1984) 
Em janeiro de 1982, a UNESCO dá mais um passo na formação deste novo campo de ação educativa de âmbito internacional com a reunião, em Grünwald (Alemanha ocidental), de representantes de 19 países que adotaram uma Declaração comum sobre a importância das mídias e a obrigação dos sistemas educacionais de ajudarem os cidadãos a melhor compreenderem estes fenômenos. Nessa reunião de alto nível, o termo "mídia-educação" é consagrado e sua necessidade reafirmada (UNESCO, 1982). A releitura deste breve documento mostra sua pertinência e força inovadora: reconhece a enorme importância das mídias na vida cotidiana em todas as esferas sociais e não condena nem aprova seu "incontestável poder". Considera sua importância na promoção da cultura contemporânea e sua função instrumental na promoção da participação ativa do cidadão na sociedade e enfatiza a responsabilidade dos "sistemas nacionais" de promoverem nos cidadãos uma compreensão crítica dos fenômenos de comunicação. A Declaração de Grünwald parte da importância crescente das mídias na sociedade, especialmente nas novas gerações, e enfatiza a necessidade de ações e políticas de mídia-educação como componente básico e condição sine qua non da formação para a cidadania. Mídia-educação é definida como uma formação para a compreensão crítica das mídias, mas também se reconhece o papel potencial das mídias na promoção da expressão criativa e da participação dos cidadãos, pondo em evidência as potencialidades democráticas dos dispositivos técnicos de mídia. Este documento fundador deixa vislumbrar a ideia da dupla dimensão da mídia-educação e, sobretudo, a consideração das mídias não só como meios de comunicação de massa, cuja leitura crítica é preciso desenvolver, mas também como meios de expressão da opinião e da criatividade pessoais, cuja apropriação é necessária assegurar a todos os cidadãos. Começa a se construir, a partir de então, a noção da mídia-educação como formação para a apropriação e uso das mídias como ferramenta: pedagógica para o professor, de criação, expressão pessoal e participação política para todos os cidadãos. Esta abordagem vai evoluir e ser construída ao longo das últimas décadas e será explicitada na Agenda de Paris, em 2007, como veremos adiante.

O mesmo documento discute as mudanças tecnológicas que levam a um grau crescente de escolha do consumidor, às possibilidades de comunicação de duplo sentido entre emissor e receptor e à individualização do acesso e dos usos que, embora referentes a satélites, televisão a 
cabo e computador, prenunciam os desenvolvimentos futuros de sistemas interativos de comunicação e redes telemáticas, concretizados hoje na rede mundial de computadores: internet. As propostas de Grünwald continuam de grande atualidade, embora o panorama técnico das mídias tenha se transformado radicalmente com o advento das TIC e suas características mais importantes: digitalização, interatividade técnica e possibilidades virtuais de interação social. A Declaração de Grünwald antecipa tais transformaçóes ao apontar os desenvolvimentos futuros das tecnologias de comunicação, citando os satélites, os sistemas de cabo, e a "combinação do computador e da televisão", como novos meios com consequências importantes no aumento das escolhas dos utilizadores. Ressalta também os impactos dos fluxos de ideias e de informações decorrentes da mundialização da cultura sobre as identidades culturais locais, e a necessidade de integrar e valorizar a diversidade cultural. A noção de mídia-educação proposta neste documento vai além das anteriores, caracterizando-se como uma "alfabetização" (literacy $)^{2}$ alargada, com uma abordagem mais integrada do ensino da linguagem e da comunicação e mais ampla, em termos de suportes técnicos, abrangendo todas as mídias modernas. O foco, porém, não é o uso pedagógico ou didático das mídias, mas as experiências midiáticas dos jovens fora da escola para, a partir delas, ensinar sobre as mídias.

Ressaltando a necessidade de mobilização e engajamento de todos os envolvidos com a socialização de crianças e jovens, ou seja, famílias, professores, comunicadores e responsáveis políticos e econômicos (decisores), no sentido de promover a construção de uma consciência crítica mais aguda de ouvintes, espectadores e leitores, a Declaração recomenda a integração entre sistemas de educação e comunicação. Nas quatro recomendaçóes, apresentadas como um "apelo", fica claro o enfoque na dimensão "objeto de estudo" da mídia-educação, embora a apropriação criativa e a participação sejam lembradas. É enfatizada a necessidade urgente de um maior comprometimento de autoridades políticas e uma maior presença da mídia-educação nas políticas públicas voltadas à educação de crianças, jovens e adultos, porém o campo da educação está ausente da recomendação relativa à pesquisa:

1. Organisar e apoiar programas integrados de educação para as mídias, do nível pré-escolar à universidade e à educação de adultos, visando a desenvolver os conhecimentos, as técnicas e as atitudes próprias para promover 
o desenvolvimento de uma consciência crítica e, por consequência, de uma competência maior entre os utilizadores das mídias eletrônicas e impressas. Idealmente, estes programas deveriam ir da análise do conteúdo das mídias até o emprego de instrumentos de expressão criativa, passando pela utilização dos canais de comunicação disponíveis, baseada em uma participação ativa.

2. Desenvolver os cursos de formação destinados aos educadores e diferentes tipos de animadores e mediadores, visando ao mesmo tempo a melhorar seu conhecimento e sua compreensão das mídias e a familiarizá-los com os métodos de ensino apropriados, levando em conta o conhecimento das mídias, muitas vezes considerável mas ainda fragmentado, que a maioria dos estudantes já possui.

3. Estimular as atividades de pesquisa e desenvolvimento que interessam à mídia-educação, em áreas como a psicologia, a sociologia e as ciências da comunicação.

4. Apoiar e reforçar as ações empreendidas ou consideradas pela UNESCO que visam a encorajar a cooperação internacional no campo da mídia-educação. (UNESCO, 1982)

Durante os anos de 1980, não faltaram declarações oficiais e experiências locais buscando pôr em prática as diretivas da Declaração de Grünwald. Profissionais de comunicação, educadores e movimentos culturais e religiosos engajaram-se em práticas inovadoras e interessantes, num movimento dinâmico e plural da sociedade civil, de caráter mais militante que oficial. No entanto, apesar destes esforços louváveis e inovadores, que significaram avanços efetivos, o balanço não é dos mais positivos e o caminho percorrido deixa insatisfeitos todos aqueles que investiram neste campo, principalmente porque não houve, durante toda esta década, políticas públicas mais efetivas que viessem imprimir às ações de mídia-educação um caráter mais sistemático e oficial, de modo a integrá-la no cotidiano da escola, indo além das experiências isoladas e militantes.

Em 1990, a UNESCO promoveu outro colóquio internacional sobre o tema, reunindo pela primeira vez representantes de muitos países, inclusive do terceiro mundo, com participantes vindos de horizontes muito diferentes, do ponto de vista geográfico e das esferas sociais que representavam: especialistas, professores-pesquisadores de diferentes 
áreas das Ciências Sociais, comunicadores e jornalistas. O Brasil, por exemplo, foi representado por uma assessora técnica da Fundação Roberto Marinho. Em virtude desta grande disparidade nos graus de representatividade, não é fácil avaliar a capacidade destes participantes de repercutir, em seus países, as recomendaçôes do Colóquio de Toulouse e, pois, a eficácia e os limites de reunióes internacionais deste tipo. Surgem, neste colóquio, novas definições de mídia-educação, tentando integrar os aspectos críticos e técnicos e suas duas dimensões, embora se possa perceber uma ênfase nos aspectos ligados à produção de mensagens midiáticas. Também é interessante notar as preocupações dos países pobres com a diversidade cultural e os problemas de cidadania e participação política:

- A mídia-educação visa a suscitar e incrementar o espírito crítico dos indivíduos (crianças, jovens e adultos) face às mídias, visando a responder às questóes: como as mídias trabalham; como são organizadas; como produzem sentido; como são peercebidos pelos públicos; como ajudar estes públicos a bem utilizá-las em diferentes contextos socioculturais? Seu objetivo essencial é desenvolver sistematicamente o espírito crítico e a criatividade, principalmente das crianças e jovens, por meio da análise da análise e da produção de obras midiáticas. Visa a gerar utilizadores mais ativos e mais críticos que poderiam contribuir à criação de uma maior variedade de produtos midiáticos.

- Mídia-educação é um processo educativo cuja finalidade é permitir aos membros de uma comunidade participarem, de modo criativo e crítico, ao nível da produção, da distribuição e da apresentação, de uma utilização das mídias tecnológicas e tradicionais, destinadas a desenvolver, libertar e também a democratizar a comunicação. (Bazalgette, Bévort \& Savino, 1992)

As recomendações deste Colóquio chamam a atenção para as características específicas dos países "em via de desenvolvimento" e sugerem algumas medidas concretas, extremamente importantes, tais como ações de formação de professores e levantamento de experiências realizadas por associações e ONGs. Fica evidente, porém, nas recomendações sobre pesquisa, a ênfase no campo da comunicação e uma relativa ausência do campo da educação, cuja implicação parece ser considerada implícita, mais como campo de aplicação de práticas que como campo 
de pesquisa e produção de conhecimento. Cabe, no entanto, ressaltar e saudar, como um avanço significativo, a alusão, pela primeira vez em documentos deste tipo, à preocupação com a escuta e a participação efetiva de crianças e jovens, no "espírito da Convenção Internacional dos Direitos da Criança e do Adolescente”, em açôes e programas de mídia-educação que lhes são destinados.

A passagem do século: internet e novíssimas TIC

Ao final do século xx, observa-se uma verdadeira "revolução tecnológica”, decorrente do avanço técnico nos campos das telecomunicações e da informática, colocando à disposição da sociedade possibilidades novas de comunicar e de produzir e difundir informação. $\mathrm{O}$ conjunto das chamadas "indústrias culturais" (rádio, cinema, televisão, impressos) vive uma mutação tecnológica sem precedentes, com a digitalização que, embora longe de ter esgotado seus efeitos, já delineia uma nova paisagem comunicacional e informacional. Do ponto de vista dos usuários, tal mutação leva um nome: internet, e se realiza em uma máquina ao mesmo tempo incrivelmente complexa e ao alcance de todos nós: o computador, à qual se acrescenta toda uma gama nova de pequenos dispositivos técnicos relacionados com as telecomunicações: telefones celulares multifuncionais, Ipod e MP3, jogos eletrônicos cada vez mais performáticos. Com a difusão crescente em ritmo exponencial, mesmo em países pobres como o Brasil, das TIC e da internet, simples usuários sem formação específica podem ter acesso a mídias sofisticadas, que permitem interatividade e acesso à informação e entretenimento quase sem limites. As mídias tornam-se mais individualizadas, impregnantes e invasivas. Da "aldeia global", passamos à "sociedade da informação ou do conhecimento" e, sobretudo, à "sociedade em rede", com suas utopias e aporias (inteligência coletiva, autonomia, democratização da cultura, realidade virtual...). As TIC e a comunicação de que elas são os veículos estão no centro destas mutações técnicas e colocam novas questôes (sociais, econômicas, políticas, educacionais), cuja compreensão é fundamental para a cidadania. O papel da mídia-educação torna-se ainda mais crucial e sua realização mais complexa, face às ilusões libertárias e igualitárias das promessas da "rede".

As novas TIC representam, evidentemente, novos desafios para a mídia-educação, que deve aprender a lidar com: uma cultura midiática 
muito mais interativa e participativa entre os jovens; fronteiras indefinidas entre a elite produtora de mensagens e a massa de consumidores; novos modos de fazer política e novas possibilidades democráticas. As formas e os sentidos que vão revestir estas novas potencialidades dependem dos modos de relações que os jovens desenvolverão com as mídias: uma direção mais democrática, crítica e criativa dependerá, em grande parte, das oportunidades de mídia-educação oferecidas às novas gerações. Cabe ressaltar que estes desenvolvimentos não são apenas resultado do avanço técnico, mas de forças e interesses econômicos, que podemos resumir com a velha fórmula da "indústria cultural", agora potencializada pela globalização da economia segundo um modelo neoliberal, levando à invasão de todas as esferas da vida social pela lógica comercial, em quase todos os países do planeta. Além das consequências do avanço técnico, transformando os espectadores em usuários, a mídia-educação também precisa incorporar em suas definições e propostas os efeitos culturais, educacionais e societais do novo Estatuto da Criança e do Adolescente, promulgado em 1989 pela ONU e progressivamente ratificado pela maioria dos países.

Tais mudanças serão consideradas, na Conferência Internacional "Educando para as mídias e para a era digital", realizada pela UNESCO em Viena, em 1999, um novo marco internacional na trajetória da mídiaeducação. Este encontro tem significativa importância porque, pela primeira vez, são ressaltados como princípios norteadores a consideração das crianças e adolescentes como parceiros efetivos (e não mais apenas como destinatários das ações) na discussão e definição de propostas, buscando assim pôr em prática o "espírito da Convenção Internacional dos Direitos da Criança e do Adolescente". Outro avanço significativo é o fato de que as mutações tecnológicas são incorporadas como elementos essenciais a considerar e não apenas como meras questões de suporte técnico. A reflexão (e a pesquisa) sobre as características técnicas das novas mídias e suas repercussões socioculturais, cognitivas, linguísticas e estéticas aparecem como um objetivo central a desenvolver. Pela primeira vez, num encontro deste tipo, os jovens desempenharam um papel efetivamente ativo, provando que eles estão aptos a criar seus próprios espaços midiáticos: eles gravaram o encontro em vídeo e realizaram um documentário que captou "a atmosfera da Conferência, o compromisso dos especialistas, a presença ativa dos jovens e mesmo um pouco do clima divertido que envolvia a todos" (UNESCO, 1999). 
Nesta Conferência, foi reafirmada a convicção de que a mídiaeducação e a participação das crianças e adolescentes são caminhos necessários e simultâneos para a realização efetiva da Convenção Internacional dos Direitos da Criança e do Adolescente, especialmente os direitos relacionados à liberdade de expressão (artigo 13), à informação (artigo 17) e à participação em decisões sobre assuntos que lhes dizem respeito (artigo 12). Apareceram diferenças de conceitos de mídia-educação e diversidade de experiências, necessidades e finalidades segundo os países e regiōes do planeta: países ricos (como a Austrália, o Canadá e vários outros da Europa) destacam objetivos de formação de indivíduos críticos, independentes e participativos, enquanto países pobres (Índia, Brasil, África do Sul) reafirmam a importância da mídia-educação para a formação da cidadania em toda a comunidade, para a democratização e a justiça social. Para estes participantes "do sul”, mídia-educação é mais ampla, incluindo não apenas as crianças na escola, mas adultos na sociedade como um todo. Apesar destas clivagens regionais, podemos encontrar, nos documentos relativos à Conferência de Viena, algumas tendências comuns:

- Mídia-educação deve emanar dos interesses dos estudantes.

- Mídia-educação significa pensamento crítico e deve levar à construção de competências de análise crítica.

- A produção de mensagens pelos estudantes é um elemento essencial para a construção do pensamento crítico e da expressão.

- Mídia-educação é necessária à participação e à democracia, ou seja, é fundamental para a cidadania.

- Mídia-educação deve considerar que a globalização, a desregulação e a privatização das mídias levaram à necessidade de novos paradigmas de educação.

- Mídia-educação deve incluir todas as mídias, não mais focalizar apenas ou principalmente as mídias impressas, mas deve incluir múltiplas "alfabetizaçôes (literacies)”. (UNESCO, 1999)

Os relatos apontam também os obstáculos mais importantes ao pleno desenvolvimento da mídia-educação e sua integração aos sistemas educacionais formais: i) falta de vontade política e apoio insuficiente dos 
organismos oficiais, que difícultam, senão impossibilitam, a integração nos espaços escolares de programas e ações de mídia-educação; ii) ausência de políticas públicas e decorrente penúria de investimentos, fazendo com que a mídia-educação não consiga superar o estágio de movimento militante, mais ou menos marginalizado segundo os países e regiōes; iii) as próprias mídias não demonstram nenhuma boa vontade com ações de mídia-educação, particularmente quando os objetivos são estimular o pensamento crítico sobre as mídias e a participação democrática. Embora extremamente cauteloso (dado o caráter oficial da Conferência), um analista atento pode advinhar, nestes relatos, a questão da má vontade dos sistemas de comunicação com a mídia-educação, já apontada nos primeiros documentos da UNESCO sobre o tema:

Seria, sem dúvida, ilusório esperar das mídias presentes em toda parte e em toda parte triunfantes que elas renunciem a seu poder e se adaptem à escola; tampouco se pode esperar muito das famílias; há somente a escola que seja teórica e praticamente capaz de conceber e executar este papel. (UNESCO, 1984, p. 7)

O fator principal da falta de empenho dos sistemas midiáticos em colaborar com ações de mídia-educação é óbvio: as mídias de massa, baseadas na publicidade comercial, precisam de audiências desavisadas, distraídas, embevecidas pelas aventuras dos heróis das ficções ou embaladas por informações fragmentadas, prontas a aceitar sem pensar os argumentos de mensagens publicitárias animadas, coloridas, envolventes. Os sistemas de mídia necessitam de públicos não-educados, acríticos, cujo tempo de cérebro suas mensagens preenchem.

Uma análise atenta dos princípios e recomendaçôes resultados dos fóruns internacionais sobre mídia-educação, mencionados acima, revela que não houve avanços significativos, em termos de ações e programas efetivamente integrados nas políticas públicas de educação e cultura, em que pesem as boas intenções dos atores destes eventos e os incontestáveis progressos conceituais, no sentido de melhor definir objetivos, princípios e conteúdos.

No Seminário euro-mediterrâneo sobre as novas implicações da mídia-educação no contexto das sociedades do conhecimento (UNESCO, 2005), houve propostas, não contempladas no documento final, sugerindo ao Programa Mentor duas ações de promoção da mídia-educação em nível internacional: realizar um estado da arte das ações de 
mídia-educação em todos os países do mundo, como base para um balanço comemorativo dos 25 anos da Declaração de Grünwald (Pinto, 2005). Como veremos, o balanço comemorativo foi realizado em Paris, em 2007, porém sem a base documental de um estado da arte. Em lugar de tal levantamento internacional, que teria permitido avançar no conhecimento e no intercâmbio de experiências, práticas e conceitos, o Programa Mentor (iniciativa da UNESCO com apoio da Comissão Européia) produziu um kit de materiais impressos destinados a formar todos os parceiros envolvidos com mídia-educação: pais, jornalistas, professores e jovens dos países da bacia mediterrânea. Embora até agora não se tenha avaliações ou relatos de sua utilização, sabemos que, em geral, este tipo de material está fadado ao insucesso, devido à sua extrema generalidade e amplitude, que acabam por torná-lo inadequado a todos os usos.

\section{Perspectivas para o futuro: Agenda de Paris e Carta de Midia-Educação}

No encontro comemorativo dos 25 anos de Grünwald (Paris, 2007), um balanço revelou que "o trajeto percorrido deixa insatisfeitos aqueles que investiram neste campo, apesar de reais avanços” (Bévort, 2008), e que é preciso tomar cuidado para não estar continuamente reinventando a roda (Buckinghan, 2007). Embora, nesta última déca$\mathrm{da}$, educadores militantes tenham realizado projetos interessantes, jornalistas e comunicadores de boa vontade tenham refletido e discutido sobre suas responsabilidades, experiências, e declarações não tenham faltado, dificilmente podemos dizer hoje que a batalha está ganha e que a mídia-educação penetrou na escola e se tornou prioridade na sociedade. Até hoje, nenhum sistema educativo integrou oficialmente a mídia-educação como uma prioridade ou conseguiu difundir seu espírito e sua importância entre os educadores em geral. Embora existam iniciativas interessantes, porém, em geral elas são paralelas, têm caráter facultativo, fora do tempo escolar e dos programas obrigatórios, e dependem da boa vontade de atores motivados: 25 anos depois de Grünwald, a mídia-educação continua a ser, na maioria dos países, uma preocupação e uma prática de educadores e jornalistas militantes (UNESCO, 2007).

Com base num estado da arte e nas discussões sobre novas perspectivas, foram elaboradas 12 recomendações de ações prioritárias para 
promover a mídia-educação, com base nas quatro grandes orientações de Grünwald, e estimular a mobilização dos atores responsáveis. Estas recomendações, resumidas abaixo, organizam-se em quatro eixos temáticos e constituem a Agenda de Paris, que reafirma a convicção de que a mídiaeducação, como parte da formação para a cidadania, é indispensável para que a sociedade "da informação seja plural, inclusiva e participativa (novos aspectos da democracia)":

\section{I - Desenvolvimento de programas integrados em todos os niveis de ensino}

1. Adotar uma definição inclusiva da mídia-educação que vá além da simples distinção entre educação pelas mídias e educação para as mídias e considere as mutações trazidas pelo desenvolvimento das TIC: novas competências, novos modos de aprender, ligados ao domínio da informação e à comunicação interativa, ou seja, à apropriação criativa e crítica das tecnologias e seus usos como meios de expressão.

2. Reforçar os vínculos entre a mídia-educação, a diversidade cultural e o respeito aos direitos humanos, no sentido de contribuir para a emancipação e a responsabilização dos indivíduos, como parte integrante da formação para a cidadania.

3. Definir as competências a construir, organizando o ensino em todos os níveis, de modo transversal e interdisciplinar, e os sistemas de avaliação, de alunos e professores, visando à melhor pertinência e eficácia.

\section{II - A formação de professores e a sensibilização dos diferentes atores da esfera social}

4. Integrar a mídia-educação à formação inicial dos professores, considerada como elemento-chave do dispositivo, devendo integrar ao mesmo tempo as dimensões conceituais e os saberes práticos e estar baseada no conhecimento das práticas midiáticas dos jovens.

5. Desenvolver métodos pedagógicos apropriados e ativos, sem receitas prontas, que implicam uma evolução no papel do professor, uma maior participação dos alunos e relações mais estreitas entre a escola e o mundo exterior.

6. Mobilizar todos os atores do sistema escolar, técnicos, administradores, etc., no sentido de sensibilizar a todos a assumir responsabilidades e legitimar as ações.

7. Mobilizar os outros atores da esfera pública, pois a mídia-educação não se limita aos espaços escolares, mas diz respeito também às famílias, associações e profissionais de mídia. 
8. Inscrever a mídia-educação no quadro da educação ao longo da vida, pois ela diz respeito também aos adultos, podendo ser vetor de uma melhor qualidade da educação continuada.

\section{III - A pesquisa e suas redes de difusão}

9. Desenvolver a mídia-educação e a pesquisa no ensino superior, em quadros interdisciplinares e em relação com estudos sobre inovações pedagógicas e sobre o impacto das TIC no ensino e na formação.

10. Criar redes de intercâmbio entre pesquisadores, de modo a capitalizar e compartilhar hipóteses e resultados de pesquisa, para contribuir à mudança de escala necessária à mídia-educação. Os resultados deveriam levar à elaboração de recomendações éticas suscetíveis a compor uma Carta internacional.

\section{IV - A cooperação internacional em açôes}

11. Organizar e tornar visíveis os intercâmbios internacionais, no sentido de difundir as "boas práticas" e os trabalhos existentes, para melhor apreender a diversidade de situaçôes concretas.

12. ensibilizar e mobilizar os atores políticos, notadamente os decisores de alto nível em todos os países. (UNESCO, 2007; texto integral em anexo)

Podemos observar, neste resumo da Agenda de Paris, alguns avanços reais, notadamente quanto à ênfase no papel dos sistemas educacionais na promoção da mídia-educação e à importância de integrar a mídia-educação na formação inicial de professores. Pela primeira vez, nos documentos oficiais internacionais deste tipo, aparece entre as principais recomendações a prioridade ao ensino formal, como espaço privilegiado de ações de mídia-educação, à formação inicial de professores (condição sine qua non de realização desta prioridade) e à pesquisa integrada ao estudo de inovações pedagógicas (e não mais a estudos de recepção de mídias, de especialistas da comunicação). Embora a experiência com relação aos resultados práticos dos documentos anteriores nos lembre que entre as recomendações e sua realização existe um grande fosso a transpor, esta Agenda aponta perspectivas mais otimistas quanto a efetivos avanços práticos e conceituais no campo da mídiaeducação. Um documento oficial de nível internacional incorpora, enfim, questões que, para muitos de nós, pesquisadores e mídia-educadores militantes de longa data, são evidentes.

É provável que o incrível progresso técnico no campo das telecomunicações e da informática, que veio revolucionar a vida social, 
provocando mutações consideráveis no mundo do trabalho, nas práticas culturais e, por consequência, nos processos educacionais, seja um fator explicativo desta significativa mudança de perspectiva nas propostas dos organismos internacionais para a mídia-educação. Frente às práticas de uso da internet, dos telefones celulares, de Ipod e MP3, dispositivos técnicos sofisticados imediatamente incorporados pelos jovens, "naturalmente", sem necessidade de formação específica, não podemos mais considerar estes jovens meramente como públicos receptores e consumidores com necessidade de "leitura crítica". Estamos diante de problemas bem mais complexos que exigem novas posturas, novos conceitos e orientaçóes, novos modos de ensinar, adequados aos novos modos de aprender que crianças e jovens desenvolvem no contato com as TIC (Belloni \& Gomes, 2008; Belloni, s/d). Em decorrência, não apenas a dupla dimensão da mídia-educação nos espaços escolares (objeto de estudo e ferramenta pedagógica) é claramente definida, mas acrescenta-se uma dimensão nova, que até então aparecia de modo implícito: a apropriação das mídias como meios ou ferramentas de expressão e participação, acessíveis a qualquer cidadão jovem ou adulto.

Cabe ainda mencionar, como exemplo de um significativo avanço político no âmbito da União Européia, o projeto Media-educ, cuja proposta era constituir um observatório de mídia-educação na Europa, a partir de uma Carta de Midia-educação, visando a reunir pessoas e grupos e criar uma dinâmica de promoção da mídia-educação (disponível em: <www.euromedialiteracy.eu/charter.php>). Esta proposta foi adotada pelo Parlamento Europeu na forma de uma resolução (dez. 2008) que retoma basicamente as recomendaçóes da Agenda de Paris, de 2007, reforça a importância e a urgência de promover a mídia-educação frente aos desafios das novas tecnologias digitais e recomenda que a Comissão Européia implemente ações e programas de promoção da mídia-educação em todos os Estados-membros (disponível em: <www. europarl.europa.eu>).

As definições mais atuais de mídia-educação se referem, de um lado, à inclusão digital, ou seja, à apropriação dos modos de operar estas "máquinas maravilhosas" que abrem as portas do mundo encantado da rede mundial de computadores, possibilitando a todos se tornarem produtores de mensagens midiáticas; e, de outro, às dimensões de $o b$ jeto de estudo, antiga "leitura crítica" de mensagens agora ampliada, e 
de ferramenta pedagógica, que diz respeito a seu uso em situações de aprendizagem, isto é, à integração aos processos educacionais. Segundo V. Reding, da Comissão Européia, "a mídia-educação é hoje tão necessária ao exercício completo de uma cidadania ativa, quanto era, no início do século 19, o domínio da leitura e da escrita" (disponível em: $<$ www.euromedialiteracy.eu>).

A Agenda de Paris reafirma, com muita ênfase, a necessidade da mídia-educação face à onipresença das mídias na vida social, principalmente na vida dos jovens, como elementos importantes da cultura contemporânea, como meios potenciais de participação ativa do cidadão e como ferramentas de expressão da criatividade pessoal. Ressalta também a importância cada vez maior da mídia-educação para lutar contra as desigualdades (sociais e regionais) de acesso às diferentes mídias e para a formação das competências necessárias ao domínio técnico e à compreensão crítica, não apenas das mensagens das mídias, como das forças político-econômicas que as estruturam. Competências estas indispensáveis para o exercício pleno da cidadania, ou seja, para estimular a participação ativa dos jovens baseada na valorização das diversidades culturais e identitárias.

O avanço mais importante, porém, realizado por esta conferência internacional, talvez seja a afirmação da mídia-educação como um direito fundamental da humanidade, que reafirma, legitima e estende aos adultos os direitos à liberdade de expressão, ao acesso à informação e à participação na vida cultural e nas decisões, contidos na Convenção Internacional dos Direitos da Criança e do Adolescente, adotada pela UNESCO em 1989. Para que este ideal seja possível e se torne realidade, é necessário que a mídia-educação seja oficializada nos sistemas de ensino, uma mudança de escala imprescindível e que deve ser acompanhada de mudanças culturais que, evidentemente, apenas a formação de professores não poderá assegurar. Será necessária uma forte vontade política, em sintonia com a demanda social, para que este ensino se inscreva nas prioridades educacionais e torne-se parte da cultura escolar. O elemento primordial para a generalização da mídia-educação e para a indispensável mudança de escala continua sendo o engajamento político, determinante para a definição das prioridades de ação e para a mobilização de recursos suficientes em todos os níveis.

Recebido em maio de 2009 e aprovado em setembro de 2009. 
Mídia-educação: conceitos, história e perspectivas

\section{Notas}

1. Consideramos como "tecnologias de informação e comunicação" (TIC) as seguintes mídias: televisão e suas variantes (videocassete, DVD, antena aberta, por assinatura), jogos de vídeo (videogames) e de computador, máquinas fotográficas e filmadoras de vídeo, Ipod, MP3, telefones celulares e redes telemáticas. Quando falamos em "mídias de massa" nos referimos principalmente à televisão e ao rádio.

2. Literacy significa alfabetização ou letramento; seu significado sempre foi polêmico: mídiaeducação significa apenas alfabetizar os públicos, ou ir além e formá-los para uma apropriação crítica e criativa? Este debate se coloca novamente frente aos novos desafios de hoje: devemos lutar por uma "alfabetização digital" (digital literacy) para todos ou por uma formação mais aprofundada? Nos documentos mais recentes da Comissão Europeia, media literacy tem sido traduzida pelo anglicismo "literacia mediática", em português de Portugal (termo inexistente em nossos dicionários), e como "compétence médiatique" em francês ("competência midiática"), que nos parece a melhor tradução para expressar a ideia de apropriação e domínio das TIC.

\section{Referências}

AGAMBEN, G. Qu'est-ce qu'un dispositif? Paris: Payot, 2007.

BAZALGETTE, C.; BÉVORT, E.; SAVINO, J. L'education aux médias dans le monde: nouvelles orientations. Paris: BFI/CLEMI/UnESCO, 1992.

BELLONI, M.L. Educação para a mídia: missão urgente da escola. Comunicação \& Sociedade, São Paulo, v. 10, n. 17, p. 36-46, 1991.

BELLONI, M.L. Programa Formação do Telespectador, kit de materiais impressos e vídeo. Brasilia, DF: UNB/CIE, 1992.

BELLONI, M.L. A espetacularização da política e a educação para a cidadania. Perspectiva, Florianópolis, n. 24, p. 23-39, 1995.

BELLONI, M.L. Formação do telespectador. Revista Noésis, Lisboa, n. 45, p. 37-40, 1998.

BELLONI, M.L. O que é mídia-educação. Campinas: Autores Associados, $2001 \mathrm{a}$.

BELLONI, M.L. A integração das tecnologias de informação e comunicação aos processos educacionais. In: BARRETO, R.G. (Org.). Tecnologias educacionais e educação a distância. Rio de Janeiro: Quartet, $2001 \mathrm{~b}$. 
BELLONI, M.L. Infância, máquinas e violência. Educação \& Sociedade, Campinas, v. 28, n. 87, p. 575-598, 2004.

BELLONI, M.L. Les cultures jeunes et les technologies de l'information et communication. Paper apresentado no Colloque Cultures Enfantines: Universalité e Diversité, Université de Nantes, France, 2007.

BELLONI, M.L. Infância e TIC: aprendizagens, autodidaxia e colaboração. Paper apresentado no Congresso Internacional em Estudos da Criança, Universidade do Minho, Portugal, 2008.

BELLONI, M.L. O que é sociologia da infância. Campinas: Autores Associados, 2009.

BELLONI, M.L. Crianças e mídias no Brasil: cenários de mudança. Florianópolis, [s.d.]. (no prelo).

BELLONI, M.L.; GOMES, N.G. Infância, mídias e aprendizagens: cenários de mudança. Educação \& Sociedade, Campinas, v. 29, n. 104, p. 717-746, 2008.

BELLONI, M.L.; SUBTIL, M.J. Dos audiovisuais à multimídia. In: Belloni, M.L. (Org.). A formação na sociedade do espetáculo. São Paulo: Loyola, 2002.

BELLONI, M.L. et al. Caracterização do público jovem das tecnologias de informação e comunicação: autodidaxia e colaboração ( $2^{a}$ fase). Florianópolis, UFSC, 2007. Relatório de pesquisa apresentado ao CNPq.

BÉVORT, E. L'education aux médias: perspectives d'un idéal 25 ans après la Déclaration de Grünwald. Paper apresentado no Colóquio "Les représentations des jeunes dans les médias en Europe de 1968 a 2008”. Strasbourg: CERIME, 2008.

BÉVORT, E. La educación en medios en Francia: dificil consolidación, perspectivas futuras. Comunicar, Huelva, v. 15, n. 28, p. 43-48, 2007.

BÉVORT, E.; BRÉDA, I. Les jeunes et l'internet. Paris: CLEMI, 2001.

BUCKINGHAN, D. De Grünwald à Paris: pour quoi l'éducation aux médias? In: Unesco. L'education aux médias: Actes, synthèse et recommendations do Encontro Internacional de Paris. Paris, 2007. 
FEILITZEN, C.V.; CARLSSON, U. (Org.). A criança e a midia: imagem, educação, participação. Brasília, DF: Unesco; São Paulo: Cortez, 2002 .

GONNET, J. Educação e midias. São Paulo: Loyola, 2004.

JACQUINOT, G. Les genres télévisuels dans l'enseignement. Paris: Hachette, 1996.

JACQUINOT, G. (Org.). Les jeunes et les médias: perspectives de la recherche dans le monde. Paris: L'Harmattan, 2002.

JACQUINOT, G. De Grünwald à Paris: pour quoi l'éducation aux médias? In: UnESCO. L'education aux médias: actes, synthèse et recommendations do Encontro Internacional de Paris. Paris, 2007.

ORGANISATION DES NATIONS UNIES POUR L'EDUCATION, LA SCIENCE ET LA CULTURE (UNESCO). L'education aux médias. Paris, 1984.

ORGANISATION DES NATIONS UNIES POUR L'EDUCATION, LA SCIENCE ET LA CULTURE (UNESCO). International Conference Educating for the Media and Digital Age. Vienna, 1999.

ORGANISATION DES NATIONS UNIES POUR L'EDUCATION, LA SCIENCE ET LA CULTURE (UNESCO). L'education aux médias: actes e synthèse do Seminário Euro-mediterrâneo. Paris, 2005.

ORGANISATION DES NATIONS UNIES POUR L'EDUCATION, LA SCIENCE ET LA CULTURE (UNESCO). L'education aux médias: actes, synthèse et recommendations do Encontro Internacional de $\mathrm{Pa}$ ris. Paris, 2007.

PERRIAULT, J. Education et nouvelles technologies. Saint-Germain-duPuy: Nathan, 2002. 